\title{
Simulation of Part Surface Residual Stress Based on Grind-Hardening Process
}

\author{
Ming-He LIU ${ }^{1, a}$, Ke ZHANG ${ }^{1}$ and Zhe YUAN ${ }^{1}$ \\ 1 School of Mechanical Engineering, Shenyang Jianzhu University, Shenyang, China, 110168 \\ rty26845@163.com
}

Keywords: Grind-hardening, Residual stress, Grinding temperature field, Hardened layer, Simulation.

\begin{abstract}
Grind-hardening is a new technology for steel parts surface enhancing which uses thermal and mechanical composite effects on the parts in the grinding process. During the process, the workpiece surface generates hardened layer which improves the surface quality. As a key performance indicator of measuring the part surface quality, the residual stress of the hardened layer affects the strength, fatigue life and corrosion performance of the part directly. Therefore, the study of residual stress in hardened layer plays an important role in the effective control of hardened layer quality. First, grinding temperature field is analysed for studying the distribution characteristics of surface residual stress after grind-hardening process. Then, different grinding parameters an effect on the temperature field is studied by establishing the mathematical model and the heat transfer model of the grinding zone temperature field. Furthermore, combined with the grinding force generated in the grinding process, the thermo-mechanical coupling analysis with finite element method is adopted to obtain the residual stress and its distribution of the part. Also, the influence mechanism of the part residual stress formation is revealed.
\end{abstract}

\section{Introduction}

Grind-hardening technology is a newly built composite processing technology. It implements hardening using grinding heat on the surface, which makes the surface temperature rising to austenitizing temperature quickly, and the then rapidly cooling to the temperature of martensitic transformation. The process improves the surface hardness and wear resistance, which achieves same performance as surface hardening treatment [1-3]. The new technology combines the grinding technology with heat treatment well, which comply the increasingly advocated concept of process integration and green manufacturing in the engineering. Grind-hardening effect is performed by hardened layer. The performance of hardened layer varies from different microstructure [4]. Brinksmeier and Brockhoff from Gernany [5-6] proposed the technology that grinding heat can be used to quench steel surface first in 1994. Then grind-hardening technology attracted the attention of scholars from different countries. Up to now, most researches focus on local microstructure and microhardness and hardness penetration depth of the workpieces [7-9].

During the grind-hardening process, the combining effect of grinding force and grinding heat produce a lot of grinding force on the part surface. After grinding process, part of the grinding force remains in the surface, which formating the grinding residual stress. It has a decisive impact on part performance, dimensional stability, fatigue strength and wear resistance.For this consideration, it has some practical significance to carry out the residual stress study on part surface.

\section{Grinding Temperature Field Model}

\section{Mathematical Model}

The grinding process is a random cutting process of many abrasive. A collection of heat source at many random grinding points can be approximately considered constant plane heat source. The total heat flux intensity of contact area is the average heat per unit area at per unit time, and is expressed as [10] 


$$
q=\frac{F_{\mathrm{t}} v_{\mathrm{s}}}{b l}
$$

The heat flux intensity of the workpiece is [11]

$$
q_{\mathrm{w}}=R_{\mathrm{w}} \frac{F_{\mathrm{t}} v_{\mathrm{s}}}{b l}
$$

where, $F_{\mathrm{t}}$ is tangential grinding force, and $v_{\mathrm{s}}$ is the grinding wheel speed. $b$ is the width of the grinding wheel or the workpiece (Whichever is the smaller value). $l$ is contact arc length, and is expressed as

$$
l=\sqrt{a_{\mathrm{p}} d_{\mathrm{s}}}
$$

The width of the heat source is equal to the width of the wheel or workpiece (Whichever is the smaller value). The heat ratio of the incoming workpiece is expressed as [12]

$$
R_{\mathrm{w}}=\frac{1}{\left[1+\frac{(k \rho c)_{\mathrm{s}}}{(k \rho c)_{\mathrm{w}}} \frac{v_{\mathrm{s}}}{v_{\mathrm{w}}}\left(\frac{A_{\mathrm{R}}}{A}\right)_{\mathrm{s}}\right]^{\frac{1}{2}}}
$$

where, $v_{w}$ is the workpiece feed rate. $(k \rho c)_{\mathrm{s}}$ and $(k \rho c)_{\mathrm{w}}$ are the thermal conductivity parameter of the grinding wheel and the workpiece, respectively, and is relation to the material properties mainly. Since plane grinding, $\left(v_{\mathrm{s}} / v_{\mathrm{w}}\right)\left(A_{\mathrm{R}} / A\right)_{\mathrm{s}} \approx 1$, therefore

$$
R_{\mathrm{w}}=\frac{1}{\left[1+\frac{(k \rho c)_{\mathrm{s}}}{(k \rho c)_{\mathrm{w}}}\right]^{\frac{1}{2}}}
$$

\section{Convective Heat Transfer Coefficient and the Coefficient of Radiation}

In the grinding process, the convective heat transfer coefficient and the coefficient of radiation are the boundary conditions. Especially when the temperature is high, radiation heat transfer temperature impact greater on the workpiece. And radiation heat transfer between the workpiece and the contact portion of the machine table cannot be ignored, which is shown in Fig. 2.

From reference [13], the convective heat transfer coefficient of the workpiece surface is

$$
h_{\mathrm{c}}=\frac{\lambda}{l} \cdot 0.664 \mathrm{Re}_{1}^{\frac{1}{2}} \operatorname{Pr}^{\frac{1}{3}}
$$

Where, $l$ is the length and of the workpiece surface. Rel is the Reynolds number, which represents relative size of the inertial force and the viscous force of the air. $\operatorname{Pr}=v / a$ is called the Prandtl number, which indicates the relative size of the air momentum diffusion capacity and diffusion capacity of the heat. $\lambda$ is the thermal conductivity of the air.

Radiation coefficient can be equivalent to the convective heat transfer coefficient, whose equation is

$$
h_{\mathrm{r}}=\frac{\sigma \varepsilon_{1} \varepsilon_{2}\left(T_{1}^{2}+T_{2}^{2}\right)\left(T_{1}+T_{2}\right)}{\varepsilon_{1}+\varepsilon_{2}-\varepsilon_{1} \varepsilon_{2}}
$$

Where, $\sigma$ is a blackbody radiation constant. $\varepsilon_{1}$ and $\varepsilon_{2}$ are emissivity of a point on the workpiece and the machine table respectively. $T_{1}$ is the absolute temperature of the machine table. And $T_{2}$ is absolute temperature of workpiece surface in contact with the machine table.

So the convective heat transfer coefficient of the workpiece surface is 


$$
h=h_{\mathrm{c}}+h_{\mathrm{r}}
$$

\section{Temperature Field Simulation Results and Discussion}

\section{Finite Element Modeling and Load}

The workpiece is modeled by Finite element software ANSYS. In the grinding process, the body structure has not changed. So hardening effect only generated on the surface. Therefore, the refined mesh on the surface of the workpiece makes the simulation results more accurate. 45 steel as the workpiece material is chosen in this study. And the model size is $90 \mathrm{~mm} \times 9 \mathrm{~mm} \times 14 \mathrm{~mm}$. Parameters for grinding process are shown in table 1.

Table 1. Grinding process parameters

\begin{tabular}{|c|c|c|c|c|c|c|}
\hline No. & 1 & 2 & 3 & 4 & 5 & 6 \\
\hline$a_{\mathrm{p}} / \mu \mathrm{m}$ & 350 & 400 & 450 & \multicolumn{2}{|c|}{400} \\
\hline$v_{\mathrm{w}} /(\mathrm{m} / \mathrm{min})$ & \multicolumn{3}{|c|}{9} & 0.54 & 0.6 & 0.66 \\
\hline
\end{tabular}

Triangle heat source model is used and optimized for simulation. In temperature field study, a moving heat source can be loaded directly on the workpiece surface [14]. To solve this problem, we suggest that heat source is moving forward continuously. Each step the heat source moving forward, load the heat flow density load on the corresponding unit of the current step instead of the former load. Besides, the last calculation result is used as the initial condition in the new step. Repeat this process step by step until realizing the moving heat source load in the finite element model. The movement of heat source is implemented by *DO, *ENDDO. Due to the temperature rising of workpiece produces temperature difference from the air outside, convective heat transfer coefficient is loaded on the workpiece surface, which is shown in Fig. 2. The ambient temperature is $T_{\infty}=20^{\circ} \mathrm{C}$.

\section{Temperature Field Simulation Results and Discussion}

Figure 1 shows the temperature nephogram of the 218th load step $(t=2.75 \mathrm{~s})$ for grind-hardening simulation. From Fig. 3, it can be seen that the highest temperature is $1240^{\circ} \mathrm{C}$, and the lowest temperature is $20^{\circ} \mathrm{C}$ in the 218 th step.

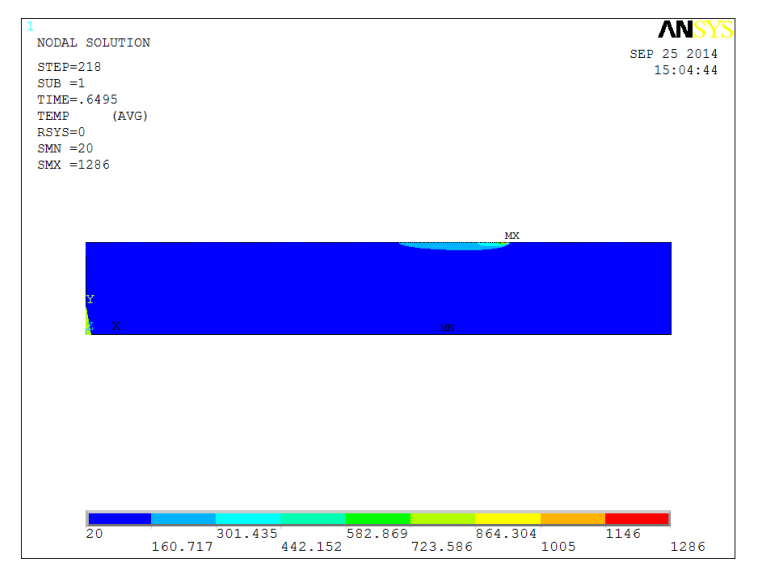

Figure 1. Temperature field simulation results for the 218 th step load when $a_{\mathrm{p}}=400 \mu \mathrm{m}, v_{\mathrm{w}}=0.6 \mathrm{~m} / \mathrm{min}$

From Figure 2, when moving heat source arrives at a certain position of the middle zone, a lot of grinding heat will generated. In this case the temperature of the workpiece may rise quickly to the maximum value $1240^{\circ} \mathrm{C}$ which is much more than $\mathrm{Ac} 3$ phase change threshold of 45 steel $\left(720^{\circ} \mathrm{C}\right)$. When the heat source moves away from this node, temperature decreases rapidly lower than martensitic transformation temperature which is affected by the thermal conductivity of the workpiece itself and convective heat with the surrounding air. After cooling, martensite is produced so as to achieving the surface hardening on the workpiece surface. 


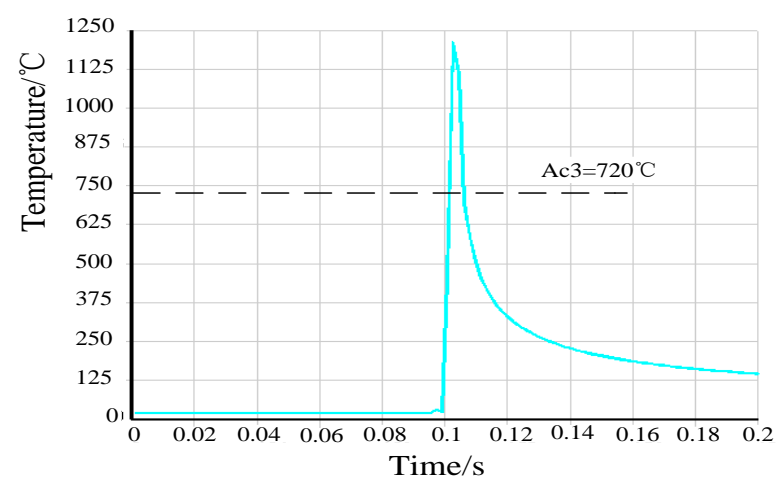

Figure 2. Temperature variation from time when $a_{\mathrm{p}}=400 \mu \mathrm{m}, v_{\mathrm{w}}=0.6 \mathrm{~m} / \mathrm{min}$

When the heating temperature of 45 steel is above Ac3, the body structure begins to change for the austenite. With the temperature dropped below Ms(transition temperature of martensite) rapidly, austenite changes into martensite. Therefore, the zone that heating temperature above Ac3 is approximate seen as grind-hardening area. Hardness penetration depth can be predicted as well. As shown in Figure 3, the surface temperature is much higher than austenite phase transition temperature. At $0.1 \mathrm{~mm}$ from the surface, the maximum temperature is higher than the Ac3 temperature. In this consideration, the region from the surface to $0.1 \mathrm{~mm}$ away from the surface is recognized as the hardened layer.

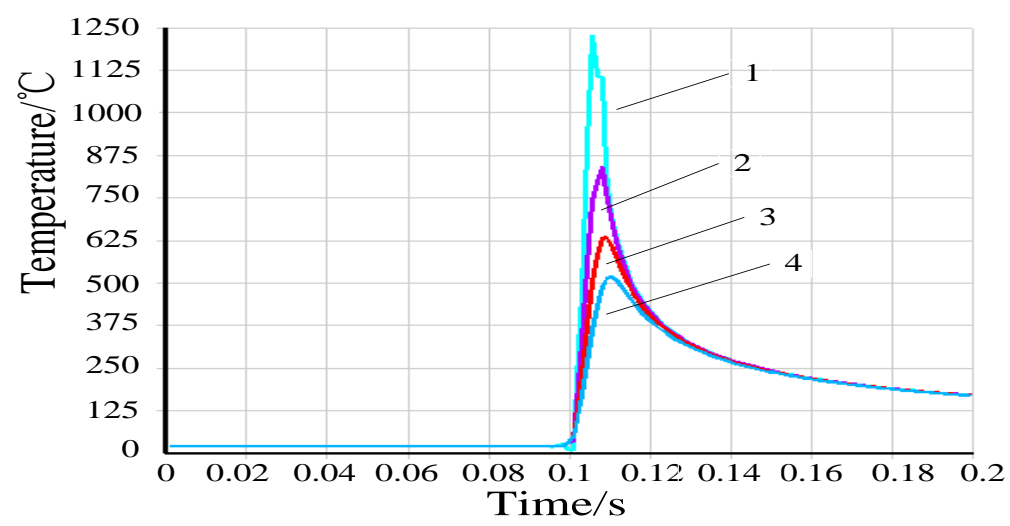

(Distance from the surface $1-0 \mathrm{~mm} 2-0.1 \mathrm{~mm} 3-0.2 \mathrm{~mm} 4-0.3 \mathrm{~mm}$ )

Figure 3. The temperature change with different depth of nodes when $a_{\mathrm{p}}=400 \mu \mathrm{m}, v_{\mathrm{w}}=0.6 \mathrm{~m} / \mathrm{min}$

\section{Residual Stress Simulation}

During the grinding process, grinding force produces from the wheel acts on the part. Meanwhile, the temperature change caused by grinding heat affects the structural deformation and material phase transformation of part, which causing changes in load and thermal boundary conditions. Therefore, the thermo-mechanical coupling analysis can reflect the residual stress distribution accurately for the part.Due to the high concentration of instantaneous heat input, greater stress will produced in the grinding process. The grinding stress field shows the material nonlinearity and geometric nonlinearity.Considering the complexity of the grinding process, the stress field is regarded as the material nonlinear transient problem for simplicity. Meanwhile, the elastoplastic model is selected for modeling. On the basis of thermoelastic analysis, the following assumptions are made:

(1) The part has no original tensile stress before the grinding process.

(2) Part material is an ideal material for isotropic, whose mechanical properties ,such as yield strength, elastic modulus, linear expansion coefficient and tangent modulus, varies with temperature . 
(3) Material deformation of viscoelastic and viscoplastic nature is ignored during the analysis. We suppose that plastic deformation satisfies the Von-Mises yield criterion.

(4) The plastic zone satisfies Prandtl-Reuss plastic flow criterion and reinforcement criterion.

Figure 4 shows the residual stress distribution on part surface. Residual tensile stress exists on part surface, whose maximum value appears in the intersection of the cutting-in zone and the middle zone.

Since the increase of grinding depth results in large temperature rise rate and temperature gradient on part surface when part goes from the cutting-in zone to the middle zone, the residual tensile stress reaches maximum value $222.2 \mathrm{MPa}, 239.5 \mathrm{MPa}$ and $272.6 \mathrm{Mpa}$ respectively with different grinding depth. The residual stress decreases first and then increases along the depth direction of the part.

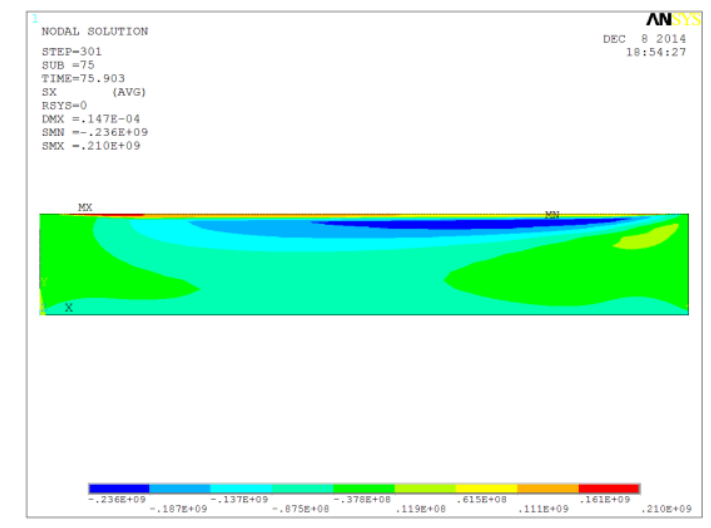

(a) $a_{\mathrm{p}}=350 \mu \mathrm{m}$

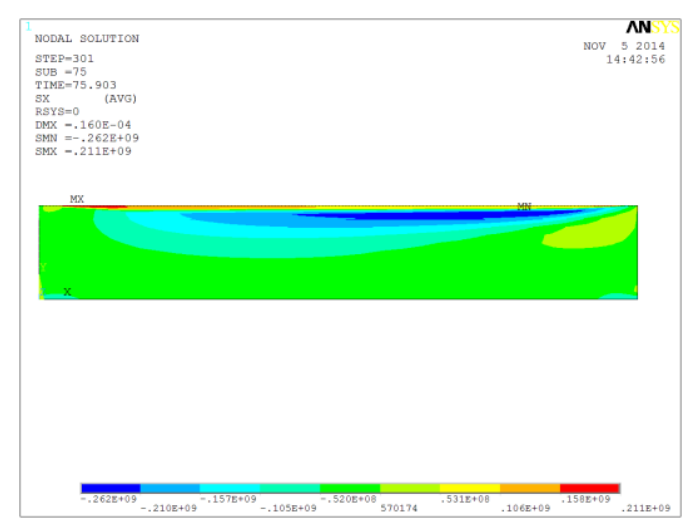

(b) $a_{\mathrm{p}}=400 \mu \mathrm{m}$

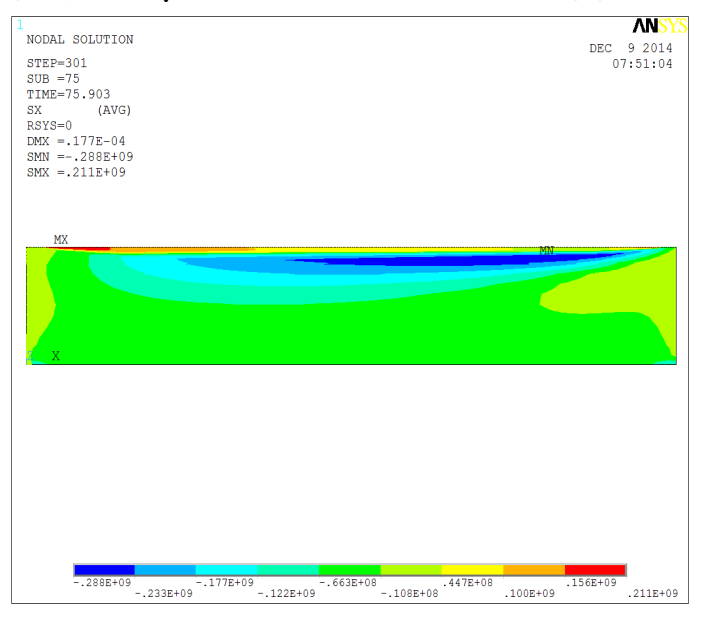

(c) $a_{\mathrm{p}}=450 \mu \mathrm{m}$

Figure 4. Residual stress under the condition of different grinding depth when $v_{\mathrm{w}}=9 \mathrm{~m} / \mathrm{min}$

Figure 5 depicts the residual stress distributions in the depth direction of the part at $a_{\mathrm{p}}=350 \mu \mathrm{m}$, $a_{\mathrm{p}}=400 \mu \mathrm{m}, a_{\mathrm{p}}=450 \mu \mathrm{m}$. Residual tensile stress is menifested on the part surface. Tensile stress shows a gradually decrease trend with the depth increases along the depth direction until transfering into compressive stress at a certain depth. Finally, the residual stress tends to zero. Also, at the same distance from the surface, the residual compressive stress increases with the grinding depth $a_{\mathrm{p}}$ increases. This is due to increase of grinding depth and temperature enhances thermal stress significantly. Generally speaking, thermal stress always produces residual tensile stresses on the surface, which increases the residual tensile stress on part surface. The greater grinding depth makes the greater hardness penetration depth, which achieve more obvious hardened effect. As the residual tensile stress on part surface increases, more internal residual compressive stress is needed to balance the residual tensile stress. From this point of view, the maximum value of residual compressive stress increases as well. 
As the distance from the surface is far, the internal residual stress will tend to zero, since it is too far to effect on the part for the grinding thermal stress, phase change force or mechanical force on the surface.

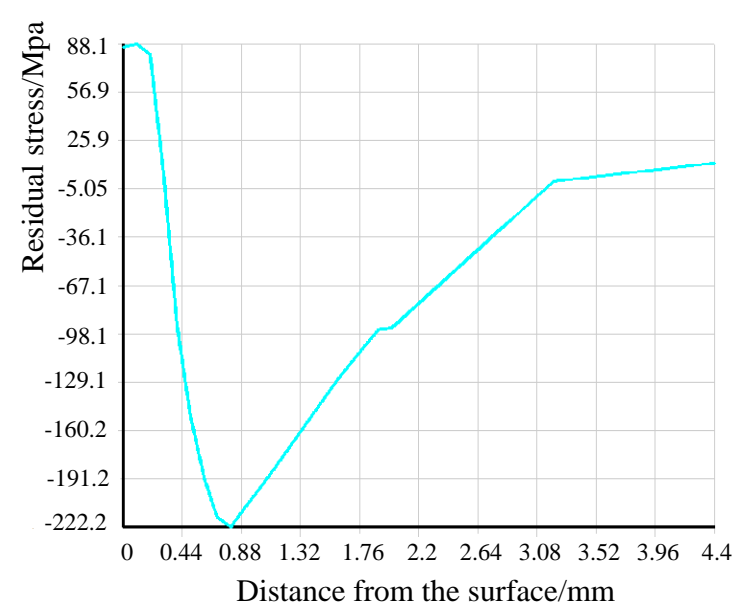

(a) $a_{\mathrm{p}}=350 \mu \mathrm{m}$

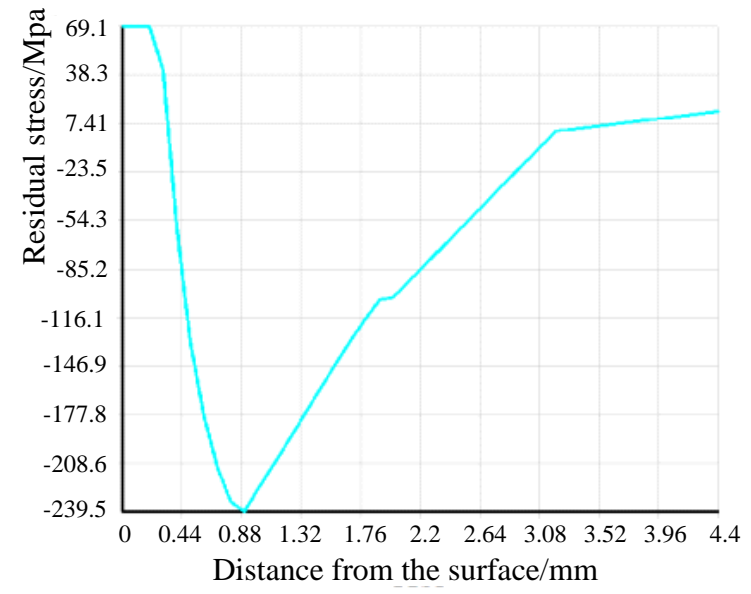

(b) $a_{\mathrm{p}}=400 \mu \mathrm{m}$

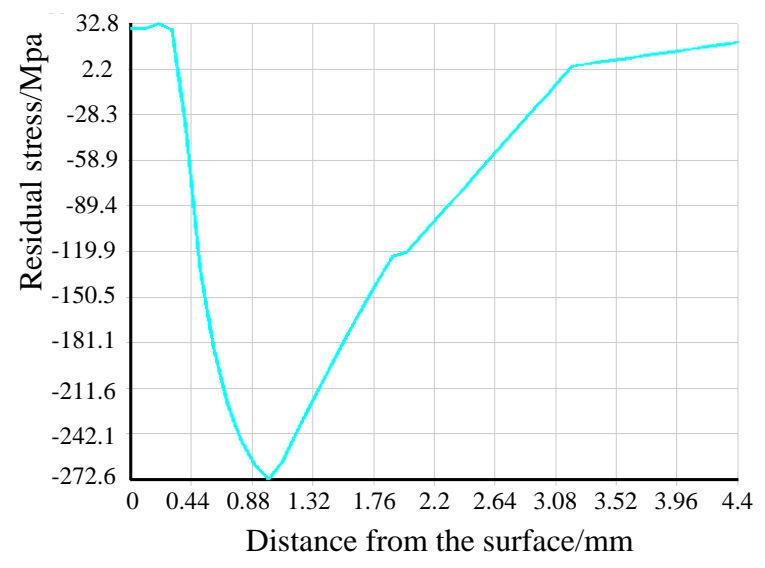

(c) $a_{\mathrm{p}}=450 \mu \mathrm{m}$

Figure 5. Residual stress distribution with the condition of different grinding depth

\section{Conclusions}

(1) From temperature field simulation, it cab be seen that the hardened layer is formed on the part surface when grinding temperature is higher than Ac3. Therefore, the zone whose temperature is higher than Ac3 is approximately regards as hardened zone. Further, hardness penetration depth can be predict as well.

(2) The simulation study on the surface residual stress of the hardened part shows that residual compressive stress exists on the part due to material expansion after grinding. While residual tensile stress is menifested on the part surface. Tensile stress shows a gradually decrease trend with the depth increases along the depth direction until transfering into compressive stress at a certain depth. Finally, the residual stress tends to zero.

\section{Acknowledgment}

This project is supported by Science and Technology Research Project for Liaoning Provincial Department of Education(No. LJZ2016007), Discipline Content Education Project of Shenyang Jianzhu Universtiy (No. XKHY2-41) and Research Funds of Shenyang Jianzhu University(No. 2015115) 


\section{References}

1. T. Nguyen, L.C. Zhang, Realisation of grinding-hardening in workpieces of curved surfacesPart1: Plunge cylindrical grinding, International Journal of Machine Tools \& Manufacture, 51(4): 309-319(2011)

2. R. Stohr, C. Heinzel, Grinding-hardening with CBN, Abrasives magazine, 6: 22-30(2002)

3. C.H. Li, Y.L. Hou, Z.R. Liu, Y.C. Ding, Investigation into temperature field of nano-zirconia ceramics precision grinding, International Journal of Abrasive Technology, 4(1): 77-89(2011)

4. T. Foeckerer, M.F. Zaeh, O.B. Zhang, A three-dimensional analytical model to predict the thermo-metallurgical effects within the surface layer during grinding and grind-hardening, International Journal of Heat and Mass Transfer, 56: 224-237(2013)

5. E. Brinksmeier, T. Brockhoff, Surface heat treatment by using advanced grinding processes, $L a$ Metallurgia Italiana, 91(4): 19-23(1999)

6. T. Brockhoff, E. Brinksmeier, Grind-hardening: a comprehensive view. CIRP, AnnalsManufacturing Technology, 48(1): 255-260(1999)

7. D.C. Fricker, T.R.C. Pearce, A.J.L. Harrison, Predicting the occurrence of grind hardening in cubic boron nitride grinding of crankshaft steel, Journal of Engineering Manufacture, 218(10): 1339-1356(2004)

8. M.F. Zaeh, E. Brinksmeier, C. Heinzel, J.W. Huntemann, T. Foeckerer, Experimental and numerical identification of process parameters of grind-hardening and resulting part distortions, WGP Ann Production Eng, 3: 271-279(2009)

9. I. Zarudi, L.C. Zhang, Mechanical property improvement of quenchable steel by grinding, Journal of Materials Science, 37(18): 3935-3943(2002)

10. C. Guo, Y. Wu, V. Varghese, S. Malkin, Temperatures and energy partition for grinding with vitrified CBN wheels, Annals of the CIRP, 48(1): 247-250(1999)

11. K. Salonitis, A. Kolios, Experimental and numerical study of grind-hardening-induced residual stresses on AISI 1045 Steel, Int J Adv Manuf Technol, 79: 1443 1452(2015)

12. A.S. Lavine, A simple model for convective cooling during the grinding process, ASME Journal of Engineering for Industry, 110(1):1-6(1988)

13. Z.L Ma, Z.T. Han, C.L. Du, Simulation of temperature field of transverse feed grinding, Manufacturing Technology\& Machine Tool, (10): 40-42(2008)

14. W.B. Rowe, S.C.E. Black, B. Mills, et al., Grinding Temperatures and Energy Partitioning. Proc.R. Soc. Lond.A. London: 1083-1104(1997) 